\title{
Review: application of current imaging modalities in the management of left-sided valvular heart disease
}

\author{
Robert Zheng, Kenya Kusunose \\ Department of Cardiovascular Medicine, Tokushima University Hospital, Tokushima, Japan \\ Contributions: (I) Conception and design: None; (II) Administrative support: None; (III) Provision of study materials or patients: None; (IV) \\ Collection and assembly of data: None; (V) Data analysis and interpretation: None; (VI) Manuscript writing: All authors; (VII) Final approval of \\ manuscript: All authors. \\ Correspondence to: Kenya Kusunose, MD, PhD. Department of Cardiovascular Medicine, Tokushima University Hospital, 2-50-1 Kuramoto, \\ Tokushima, Japan. Email: kusunosek@tokushima-u.ac.jp.
}

\begin{abstract}
In terms of valvular heart disease (VHD) imaging, transthoracic echocardiography (TTE) is the preferred first choice because of its widespread availability. Other modalities, such as transesophageal echocardiography, computed tomography and magnetic resonance imaging, have played a supplementary role in diagnosis for severity, deciding the timing/type of treatment, detection of post procedural complications, and prognostic predictions. However, there are few consensuses on how to employ these modalities, as the evidence is not extensive as that for TTE. On the other hand, these imaging modalities also have their own unique strengths. If employed properly, these modalities have the potential to play a more prominent role in clinical decision making. In this review, we focus on the potential, limitations and application of current imaging modalities in the management of left-sided VHD
\end{abstract}

Keywords: Valvular heart disease (VHD); echocardiography; computed tomography (CT); magnetic resonance imaging (MRI)

Submitted Nov 25, 2019. Accepted for publication Jan 31, 2020.

doi: $10.21037 / \mathrm{cdt} .2020 .02 .04$

View this article at: http://dx.doi.org/10.21037/cdt.2020.02.04

\section{Introduction}

In the current field of valvular heart disease (VHD), the development of innovative techniques, such as transcatheter aortic valve replacement (TAVR) and transcatheter mitral valve repair (TMVR), have created new treatment options for high-risk patients previously considered unsuitable for invasive intervention. These advances have benefitted these patients, leading to improved quality of life (QOL) and better clinical outcomes. In terms of VHD imaging, transthoracic echocardiography (TTE) is the preferred first choice because of its widespread availability (Figure 1). Other modalities, such as transesophageal echocardiography (TEE), computed tomography (CT) and magnetic resonance imaging (MRI), have played a supplementary role in diagnosis for severity, deciding the timing/type of treatment, detection of post procedural complications, and prognostic predictions (Figure 2). However, there are few consensuses on how to employ these modalities, as the evidence is not extensive as that for TTE. In this review, we focus on the potential, limitations and application of current imaging modalities in the management of left-sided VHD.

\section{Strengths and limitations of imaging modalities}

The strengths and limitations of each modality are listed in Table 1. TTE has been the first-line for imaging in VHD due to its inexpensiveness, simplicity and availability. It provides real-time hemodynamic information, and can be employed with exercise or dobutamine stress testing (1-4). It has decent spatial resolution, providing detailed images of valvular structures for determining the etiology of the disease. On the other hand, TTE tends to have a limited acoustic window, limited view of the right heart, and large artefacts due to calcification/devices. TTE also has a 

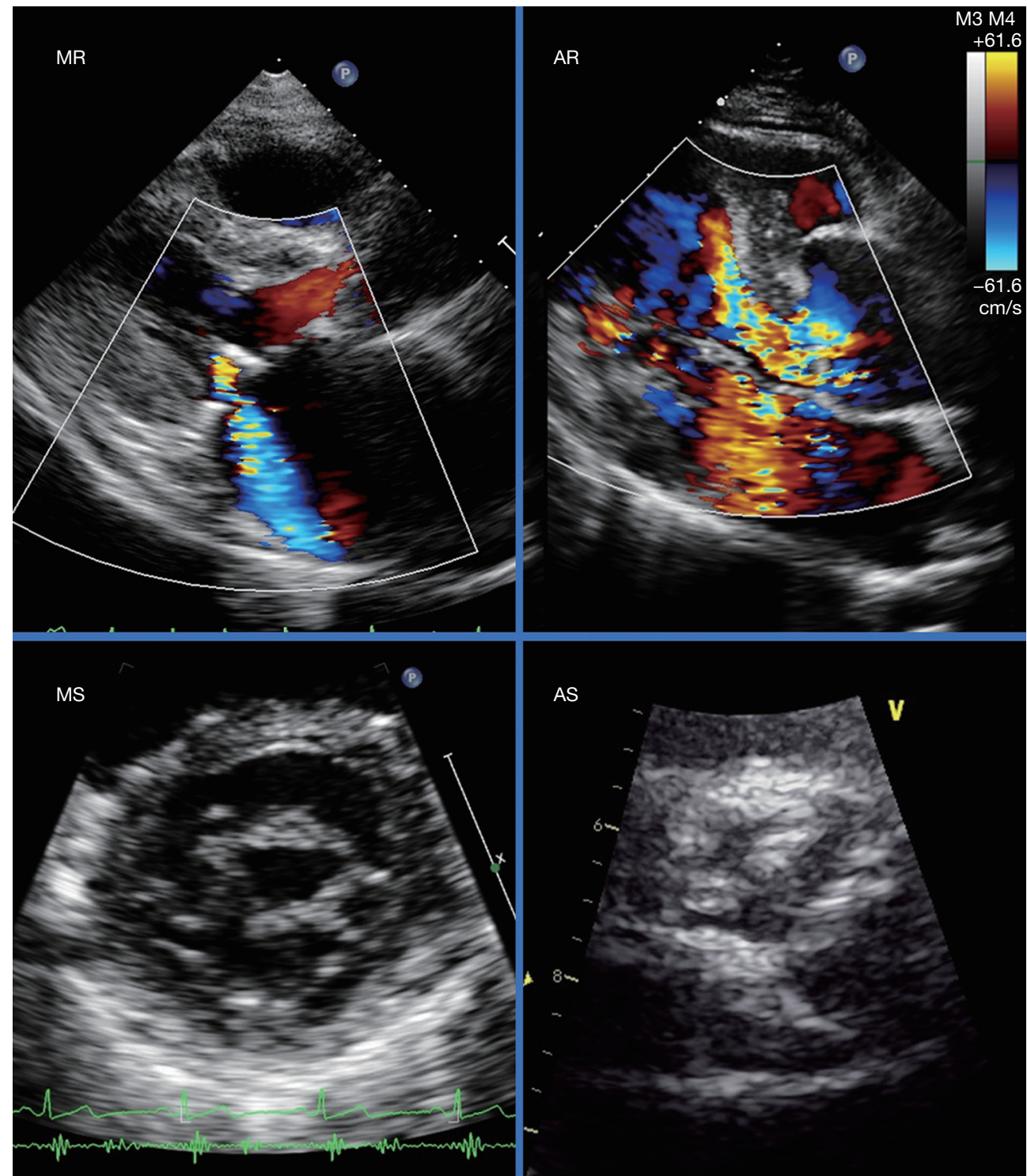

Figure 1 Echocardiographic images for valvular heart disease. Echocardiography is the first-line imaging modality for assessment of valvular heart disease. AR, aortic regurgitation; MR, mitral regurgitation; AS, aortic stenosis; MS, mitral stenosis.

considerable inter-/intra-observer variability and is difficult to use in assessment of eccentric jet flows. Some parameters obtained by TTE are calculated based on anatomical assumptions, usually resulting in over/underestimation compared with measurements obtained with TEE, CT or MRI (5-7).

TEE does not have the same restrictions of acoustic windows like TTE, and can provide detailed imaging of the right heart. With 3D imaging, regurgitation jets and highly mobile structures (such as vegetation and embolism) are more clearly detailed. Measurements (dimensions, volumes and velocities) show a good correlation with those obtained via CT or MRI. TEE also provides valuable real-time guidance for device placement in transcatheter procedures such as TAVR and TMVR. However, TEE usually requires sedation, making it unsuitable for highly frail patients or patients with an unstable hemodynamic state. TEE is also risky to perform in patients with esophageal hernias, varices and etc. (Table 2). This modality had many anatomical "blind spots", unable to provide accurate imaging of vascular structures outside of the heart. In addition, 3D TEE is useful to assess the tricuspid valve morphology for 

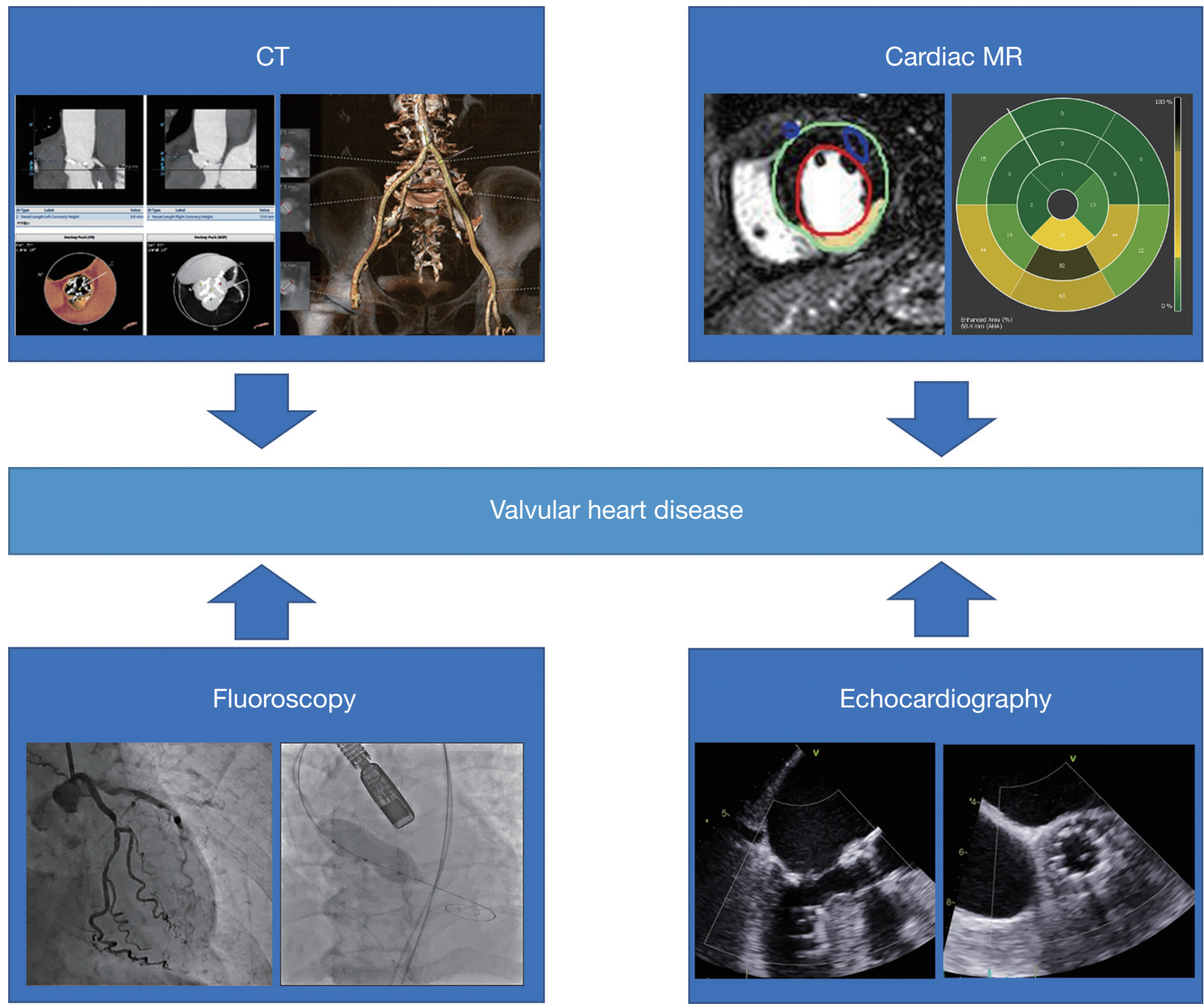

Valvular heart disease

Figure 2 Multimodality assessment for valvular heart disease. Echocardiography, computed tomography and magnetic resonance imaging have played a supplementary role in diagnosis for severity, deciding the timing/type of treatment, detection of post procedural complications, and prognostic predictions. CT, computed tomography; MR, magnetic resonance.

the intervention (8).

CT with its high spatial resolution, is a swift and accurate tool for assessing the physical characteristics of the heart and surrounding structures (9). It provides additional detail on the degree/extent of calcifications and presence of coronary artery disease. Its excellent spatial resolution enables accurate measurements of valvular orifice and surrounding area, useful for planning the optimal approach and landing zones for device implantation. As a typical example of CT usage, Casset et al., reported a reduction in stroke occurrence, vascular complications, paravalvular aortic regurgitation (AR) after integrating CT data with measurements acquired via TTE and TEE (10). In spite of its superior spatial resolution, CT is unable to provide detailed information on the tissue composition of the valve and myocardium. Another drawback for this modality is the requirement of contrast agents and ionizing radiation.

MRI boasts a high reproducibility, simultaneously visualizes both the right and left heart and provides detailed information on myocardial mass and fibrosis. It does not use 
Table 1 Characteristics of cardiac imaging modalities

\begin{tabular}{|c|c|c|c|c|}
\hline Modality & TTE & TEE & CT & MRI \\
\hline \multirow{4}{*}{ Strengths } & $\begin{array}{l}\text { Can provide information } \\
\text { on hemodynamic effects }\end{array}$ & $\begin{array}{l}\text { Enables 3D analysis of } \\
\text { valve and jet flows }\end{array}$ & $\begin{array}{l}\text { Images are obtained } \\
\text { swiftly }\end{array}$ & $\begin{array}{l}\text { Provides information } \\
\text { on myocardial function/ } \\
\text { composition (fibrosis, } \\
\text { remodeling) }\end{array}$ \\
\hline & $\begin{array}{l}\text { Can be employed with } \\
\text { stress testing }\end{array}$ & $\begin{array}{l}\text { Can view highly mobile or } \\
\text { small structures (vegetation, } \\
\text { embolism, etc.) }\end{array}$ & $\begin{array}{l}\text { Provides information of } \\
\text { possible routes of access, } \\
\text { and can be utilized in } \\
\text { simulations }\end{array}$ & $\begin{array}{l}\text { No use of radiation, does not } \\
\text { necessarily require contrast } \\
\text { agents }\end{array}$ \\
\hline & \multirow[t]{2}{*}{$\begin{array}{l}\text { Provides information on } \\
\text { valve structure }\end{array}$} & \multirow[t]{2}{*}{ Can analyze RV function } & \multirow[t]{2}{*}{$\begin{array}{l}\text { Enables accurate analysis } \\
\text { of calcified areas }\end{array}$} & $\begin{array}{l}\text { Enables relatively accurate } \\
\text { measurement of physical } \\
\text { dimensions }\end{array}$ \\
\hline & & & & $\begin{array}{l}\text { Can assess eccentric jets (by } \\
\text { using stroke volumes) }\end{array}$ \\
\hline \multirow[t]{6}{*}{ Limitations } & Limited acoustic window & $\begin{array}{l}\text { Highly invasive and requires } \\
\text { sedation }\end{array}$ & $\begin{array}{l}\text { Requires use of contrast } \\
\text { agent (difficult to use in } \\
\text { patients with decreased } \\
\text { renal function or allergy) }\end{array}$ & $\begin{array}{l}\text { Limited availability (in terms of } \\
\text { both hardware and software) }\end{array}$ \\
\hline & $\begin{array}{l}\text { Large acoustic shadow } \\
\text { by calcification or } \\
\text { devices }\end{array}$ & $\begin{array}{l}\text { Risk to employ in patients } \\
\text { with esophageal hernia/ } \\
\text { varices }\end{array}$ & $\begin{array}{l}\text { Difficult to employ in } \\
\text { cases with multiple VHD }\end{array}$ & Difficult to assess calcification \\
\hline & Difficult to assess RV & & & $\begin{array}{l}\text { Difficult to use ECG gating in } \\
\text { cases with arrhythmia }\end{array}$ \\
\hline & \multirow[t]{3}{*}{$\begin{array}{l}\text { Difficult to assess } \\
\text { eccentric jets }\end{array}$} & & & $\begin{array}{l}\text { Difficult to accurately measure } \\
\text { peak flow velocities in } \\
\text { turbulent jets }\end{array}$ \\
\hline & & & & $\begin{array}{l}\text { Difficult to assess small, highly } \\
\text { mobile structures due to } \\
\text { insufficient spatial resolution }\end{array}$ \\
\hline & & & & $\begin{array}{l}\text { Lack of consensus regarding } \\
\text { grading of severity }\end{array}$ \\
\hline
\end{tabular}

Table 1 (continued) 
Table 1 (continued)

\begin{tabular}{|c|c|c|c|c|}
\hline Modality & TTE & TEE & CT & MRI \\
\hline $\begin{array}{l}\text { Role in post-operative } \\
\text { management }\end{array}$ & $\begin{array}{l}\text { Can be used to screen } \\
\text { for the presence } \\
\text { of post-procedural } \\
\text { comorbidities }\end{array}$ & $\begin{array}{l}\text { Can assess the location } \\
\text { and degree of paravalvular } \\
\text { leakage }\end{array}$ & $\begin{array}{l}\text { Can provide guidance } \\
\text { for planning paravalvular } \\
\text { leakage closure }\end{array}$ & $\begin{array}{l}\text { Can follow changes in aortic } \\
\text { dimensions post AVR }\end{array}$ \\
\hline
\end{tabular}

TTE, transthoracic echocardiography; TEE, transesophageal echocardiography; MRI, magnetic resonance imaging; CT, computed tomography; LV, left ventricular; RV, right ventricular; VHD, valvular heart disease; ECG, electrocardiogram; GLS, global longitudinal strain; TAVR, transcatheter aortic valve replacement; LVOT, left ventricular outflow tract; TMVR, transcatheter mitral valve repair; AVR, aortic valve replacement.

Table 2 Check list of TEE

Risk of procedure
Esophageal issues: hernias, dysphagia, ulcers and etc.
Cirrhosis or varices
Sleep apnea or oxygen requirement
Cervical spine issues
Dentures or loose teeth
History of thoracic radiation treatment
Coagulation therapy
Low platelet counts
For females <50 years, possibility of pregnancy
Allergies

TEE, transesophageal echocardiography.

ionizing radiation and does not necessarily require contrast agents. By using direct (for AR) and indirect [for mitral regurgitation (MR)] methods, MRI can accurately calculate regurgitation volumes, even in cases with multiple or eccentric jets. Major limitations for this modality are, high costs, limited availability (of both hardware and software, and analysis expertise), unsuitability with implanted devices and claustrophobic patients. Compared with CT, it has limited spatial resolution, making imaging of highly mobile or thin structures (valve leaflets, vegetations, embolisms, and etc.) extremely difficult $(11,12)$. Velocity and volume measurements tend to fluctuate in cases with arrhythmias or turbulent flows (13). Generally, measurements obtained with this modality are more accurate than TTE, however currently there is no consensus for cutoff values in determining disease severity. For example, Myerson et al. reported that $\mathrm{AR}$ quantified with cardiovascular magnetic resonance $(\mathrm{CMR})$ identified clinical outcomes with high accuracy, $85 \%$ of subjects with regurgitant fraction $>33 \%$ progressing to surgery, compared to $8 \%$ of subjects with regurgitant fraction $<33 \%$ (14). Harris et al. reported that CMR-derived regurgitant volume for chronic AR was more strongly associated with clinical outcomes than that obtained with TTE (15). According to these results, we can apply the CMR assessment when the grading is undetermined in AR.

Fluoroscopy/catheterization can provide real-time analysis of the coronary arteries and hemodynamic state, and can be employed with stress testing. However, this highly invasive modality requires much radiation exposure and has a constant risk of bleeding/thrombotic complications.

\section{What to look for?}

The overview of check points for VHD imaging in TAVR 
Table 3 Points of focus prior and post-intervention in AS

\begin{tabular}{ll}
\hline When & Points of focus \\
\hline Prior to & Severity (peak velocity, regurgitant volume, etc.) \\
& Morphology and number of leaflets \\
& Calcification of leaflets and surrounding \\
structure & Dimensions and shape of annulus and LVOT \\
& Possible routes of approach (in cases of \\
& transcatheter interventions) \\
& Etiology of the VHD in question \\
& LV, RV function \\
& Coincidental coronary lesions, thrombi, \\
& vegetations \\
& Signs of remodeling, fibrosis in myocardium \\
& Dimensions of Valsalva sinus, aorta, coronary \\
height & Transvalvular/paravalvular leakage \\
Post- & Changes in position of prosthetic valve \\
follow-up & Changes in dimensions of aorta \\
& Changes in LV function (LVEF, remodeling) \\
\hline AS, &
\end{tabular}

AS, aortic stenosis; LVOT, left ventricular outflow tract; VHD, valvular heart disease; LV, left ventricular; RV, right ventricular; LVEF, left ventricular ejection fraction.

are shown in Table 3. In aortic stenosis (AS), in addition to peak aortic valve (AV) velocity and valvular orifice area, observations should be made on leaflet shape/ calcification, shape and size of Valsalva sinus, appearance and angle of the ascending aorta and position of the coronary ostium. In cases where TAVR is a viable option, peripheral arteries should also be observed as possible points of access. Even in asymptomatic patients or moderate AS, signs of increased myocardial burden, such as changes in myocardial strain in TTE or myocardial fibrosis in MRI, play a crucial role in determining the optimal timing for intervention $(16,17)$. In asymptomatic AS with extensive myocardial fibrosis, the current guideline recommendation for aortic valve replacement (AVR) is not feasible for early risk stratification (18). AS is characterized by a significant increase in diffuse myocardial fibrosis (DMF) then followed by focal myocardial fibrosis (FMF). DMF can be assessed with T1 mapping, while FMF is defined by late gadolinium enhancement. DMF is thought to be reversible, while
FMF is thought to be irreversible, with the latter associated with significantly poor postoperative outcomes (19-22). In a similar manner, regional and global longitudinal strain (GLS) are also reported to have a greater and earlier diagnostic power than left ventricular ejection fraction (LVEF) $(23,24)$. There are also reports of using left atrial (LA) global strain and LA dilation for prediction of AS prognosis, however, whether this is a suitable sign for early intervention remains to be validated $(25,26)$.

In $\mathrm{AR}$, there have been similar findings of myocardial fibrosis to AS in MRI. In addition to valvular morphology and regurgitant volume, observation of the aorta is also important in determining the etiology of the disease. In chronic $\mathrm{AR}, \mathrm{LV}$ volumetric data obtained via echocardiography ( $\mathrm{LV}$ end-systolic volume index $\geq 45 \mathrm{~mL} / \mathrm{m}^{2}$ ) or CMR (LV enddiastolic volume $>246 \mathrm{~mL}$ with regurgitant fraction $>33 \%$ ) may be useful for identifying patients at increased risk of clinical progression (27). Late-gadolinium enhancement in CMR has been associated with persisting symptoms, poor LV recovery, compromised event-free survival, and increased risk of mortality in surgical AR cohorts. Subnormal LV longitudinal deformation detected by speckle-tracking echocardiography may predict disease progression in asymptomatic patients $(28,29)$. Both of these signs may occur prior to overt LV dysfunction, being possible determinants for early intervention (30).

In MR, assessment of the valve, left ventricle, left atrium, chordae tendineae and papillary muscles are all important to determine the etiology of the disease. It is also crucial to determine the type of MR (primary or secondary, ischemic or nonischemic) due to the differences in treatment options and post-procedural prognosis (31-33). Past reports have suggested that successful repair for secondary MR was less likely in the presence of mitral valve (MV) deformation, global LV remodeling and local LV remodeling (34). Similar to AR, MRI provides accurate quantifications of regurgitation volumes, with Myerson et al., reporting that by using CMR quantification, $91 \%$ of subjects with regurgitant volume $\leq 55 \mathrm{~mL}$ survived to 5 years without surgery compared with only $21 \%$ with regurgitant volume $>55 \mathrm{~mL}$ (35). If TMVR is considered, observation of the left ventricular outflow tract (LVOT) and mitral annulus are also necessary for predicting LVOT obstruction post procedure (36). As in the case of AS and AR, myocardial fibrosis may play a role in long-term clinical outcomes of $M R$, with its clinical value currently being validated in the mitral FINDER study (a multi-center, prospective, crosssectional comparison of patients prior to and 9 months 
following surgery for chronic severe primary degenerative MR) (37). In the echocardiographic field, GLS is also a strong predictor of post-operative outcome. Several investigators reported that LV GLS was a significant predictor of cardiac outcome, regardless of $\mathrm{LV}$ dysfunction, atrial fibrillation or surgery type $(38,39)$.

In mitral stenosis (MS), valve morphology can provide information on disease etiology. Dilation of the left atrium is reported to increase the risk of atrial fibrillation and embolisms, and may be a sign for the necessity of intervention (40). The preferred method of treatment for MS is percutaneous mitral balloon valvuloplasty (PMBV). TTE and TEE play a crucial role in evaluating to suitability for PMBV. The Wilkins score, based on echocardiographic findings, such as leaflet mobility, valvular thickening, subvalvular thickening and calcification, is used to predict $\mathrm{PMBV}$ success, with a score of $\leq 8$ predicting favorable outcomes. Assessment of contradictions (atrial thrombi, severe or bicommissural calcification, mitral valve area $(M V A)>1.5 \mathrm{~cm}^{2}$, greater than mild $M R$, absence of commissural fusion, severe concomitant aortic/tricuspid disease, and etc.) are also performed with echocardiography (41). The atrial remodeling may be different in MS compared with MR, with one group reporting a larger post-operative LAV reduction in MR compared with MS (42).

Mitral annular calcification (MAC) is estimated to be prevalent in 3-6\% of patients undergoing $\mathrm{MV}$ replacement. The presence of extensive MAC is considered to be associated with worse surgical outcomes, with paravalvular leakage (PVL) and clinical deterioration (43). When considering interventional treatment in $\mathrm{MV}$ disease, mitral annular calcification may also become a factor in post-procedural complications, making it a necessity to evaluate the degree and extent of calcification in the mitral annulus along with the valve. Even in patients undergoing TAVR, the presence of MAC cannot be overlooked, with one group reporting severe MAC to be an independent strong predictor of overall mortality and new pacemaker implantation post-TAVR (44).

\section{When and how to employ?}

In the current clinical setting, TTE should be the preferred first choice for diagnosis of VHD. Other modalities can be considered when TTE were inconclusive. These modalities should play a more prominent role obtaining information crucial for clinical decision making (Figure 3). If the image quality from TTE is insufficient, further evaluation can be provided with TEE or MRI. CT and fluoroscopy can be utilized to assess cardiac ischemia, while MRI can provide extensive imaging of the myocardium. In cases where there is a mismatch between severity determined by TTE and clinical symptoms, stress echocardiography can be considered to evaluate the hemodynamic effect of the disease, or MRI can be employed to reevaluate the flow volume obtained from TTE (45). When transcatheter intervention is taken into consideration, CT is useful for pre-procedural planning, searching for suitable vascular access routes and optimal landing zones. Signs of myocardial fibrosis, observed with contrast-enhanced MRI, provides hints for estimating post-procedural prognosis and the possibility of $L V$ reverse remodeling.

\section{Roles in post-procedural management}

Especially in AS, important points prior to interventions and post procedural follow-up were shown in Table 3. Changes in the aorta and device, presence and degree of PVL, changes in LV function and mass should be assessed. Follow-up of dimensions in the aorta and valves can be performed with CT and MRI, which are highly reproducible. TTE can identify PVL, but fails to accurately quantify leakage severity in cases with multiple jets. Regurgitation volume of PVL can be more accurately assessed with MRI, and to some extent aortography (which can be performed immediately after device deployment). 3D imaging obtained via CT and TEE can help in determining the number and location of leaks. These images are crucial in planning secondary intervention for severe PVL (46). Myocardial strain evaluated with TTE, and reverse remodeling observed via MRI may provide estimates for LV function recovery and long-term prognosis. Nucifora et al., reported a long-term improvement of $\mathrm{LV}$ myocardial deformation and regression of left ventricular hypertrophy (LVH) in both TAVR and surgical aortic valve replacement (SAVR) patients (47).

In TAVR, significant residual AR is associated with greater mortality. A meta-analysis conducted by Takagi et al. reported a 2 -fold increase in 1-year all-cause mortality for patients with moderate to severe paravalvular AR postTAVR (48). However, determining AR severity postTAVR using TTE is challenging, due to the presence of multiple eccentric jets that are parallel and irregular in shape. Considerable artefacts caused by the prosthetic valve and calcifications also obscure significant regurgitant jets 


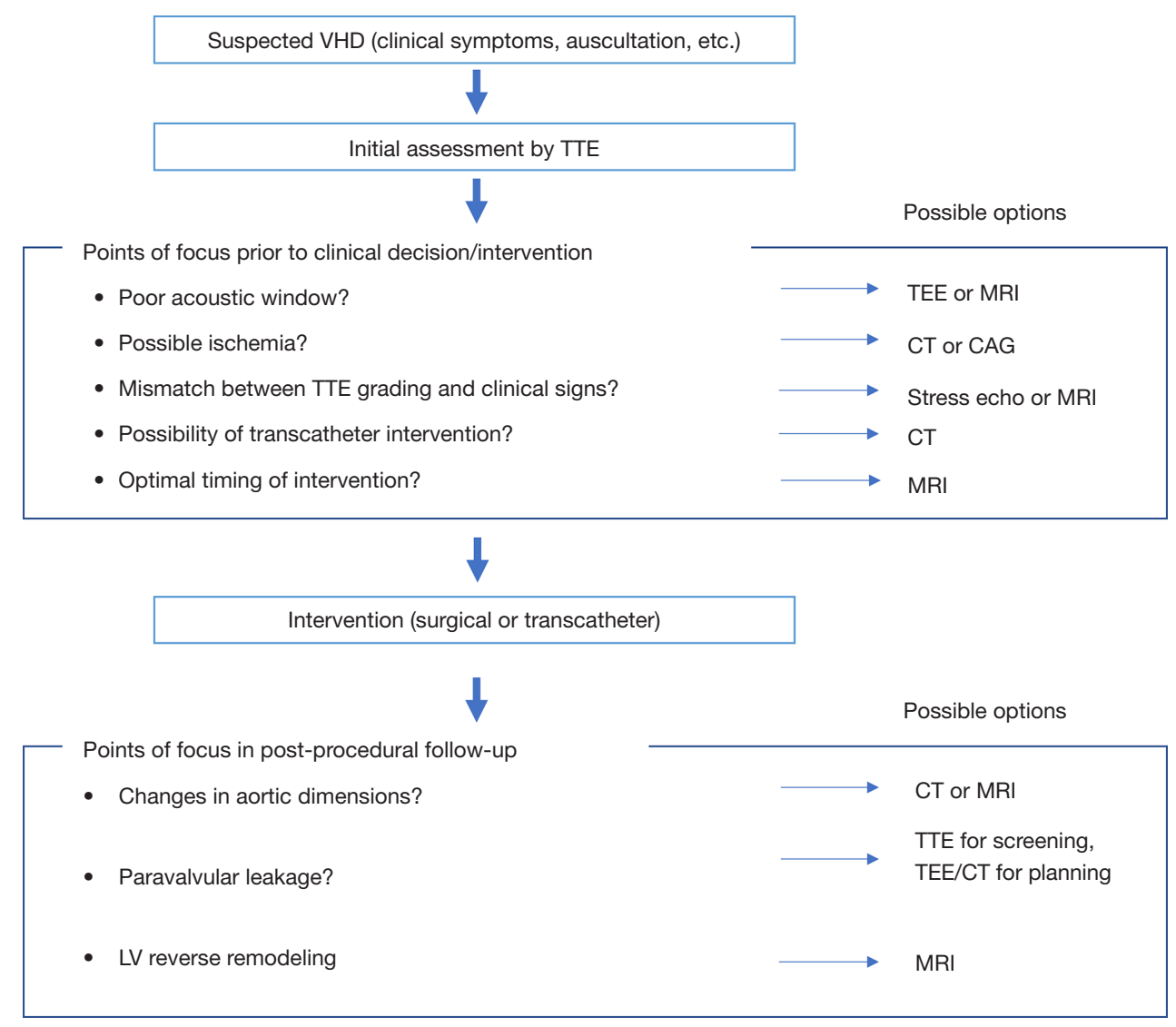

Figure 3 A chart of multimodality imaging for clinical decision making. Multimodalities should play a more prominent role obtaining information crucial for clinical decision making. TTE, transthoracic echocardiography; TEE, transesophageal echocardiography; MRI, magnetic resonance imaging; CT, computed tomography; CAG, coronary angiography; LV, left ventricular.

and result in underestimation of severity (49). Ribeiro et al. reported that residual AR with a regurgitation fraction greater than $30 \%$ best predicted poorer clinical outcomes, with CMR performed 40 days post-TAVR showing a greater association than early TTE follow-up (50). Aortic root angiography also shows decent accuracy post-TAVR. However, this method is characterized by significant overlap among Sellers classifications and has a considerable intra-/ inter-observer variability on assessing AR post-TAVR (51). In addition to residual $\mathrm{AR}$, some attention should also be paid to concomitant valvular diseases, such as MR. However, the clinical value of these VHDs post-TAVR is still up for debate (52).

\section{Conclusions}

Currently, TTE is still the first-line imaging modality for assessment of VHD. In the guidelines, other imaging modalities would have been considered when TTE imaging was inconclusive, hence playing second fiddle to TTE. However, these modalities also have their own unique strengths. If employed properly, these modalities have the potential to play a more prominent role in clinical decision making.

\section{Acknowledgments}

Thank you for the invitation to participate in the focused issue "Heart Valve Disease" led by Dr. Deborah H. Kwon, Dr. Bo Xu and Dr. Rhonda Miyasaka.

Funding: None.

\section{Footnote}

Provenance and Peer Review: This article was commissioned by the Guest Editors (Deborah H. Kwon and Bo Xu) for the series "Heart Valve Disease" published in Cardiovascular 
Diagnosis and Therapy. The article has undergone external peer review.

Conflicts of Interest: Both authors have completed the ICMJE uniform disclosure form (available at http://dx.doi. org/10.21037/cdt.2020.02.04). The series "Heart Valve Disease" was commissioned by the editorial office without any funding or sponsorship. The authors have no other conflicts of interest to declare.

Ethical Statement: The authors are accountable for all aspects of the work in ensuring that questions related to the accuracy or integrity of any part of the work are appropriately investigated and resolved. All procedures followed were in accordance with the ethical standards of the responsible committee on human experimentation (institutional and national) and with the Helsinki Declaration of 1964 and later versions.

Open Access Statement: This is an Open Access article distributed in accordance with the Creative Commons Attribution-NonCommercial-NoDerivs 4.0 International License (CC BY-NC-ND 4.0), which permits the noncommercial replication and distribution of the article with the strict proviso that no changes or edits are made and the original work is properly cited (including links to both the formal publication through the relevant DOI and the license). See: https://creativecommons.org/licenses/by-nc-nd/4.0/.

\section{References}

1. Zoghbi WA, Adams D, Bonow RO, et al. Recommendations for Noninvasive Evaluation of Native Valvular Regurgitation: A Report from the American Society of Echocardiography Developed in Collaboration with the Society for Cardiovascular Magnetic Resonance. J Am Soc Echocardiogr 2017;30:303-71.

2. Onishi T, Sengoku K, Ichibori Y, et al. The role of echocardiography in transcatheter aortic valve implantation. Cardiovasc Diagn Ther 2018;8:3-17.

3. Kusunose K, Yamada H, Nishio S, et al. Preload Stress Echocardiography Predicts Outcomes in Patients With Preserved Ejection Fraction and Low-Gradient Aortic Stenosis. Circ Cardiovasc Imaging 2017;10:e006690.

4. Kusunose K. Clinical application of stress echocardiography for valvular heart disease. J Med Ultrason (2001) 2020;47:81-9.

5. Cawley PJ, Hamilton-Craig C, Owens DS, et al.
Prospective comparison of valve regurgitation quantitation by cardiac magnetic resonance imaging and transthoracic echocardiography. Circ Cardiovasc Imaging 2013;6:48-57.

6. Penicka M, Vecera J, Mirica DC, et al. Prognostic Implications of Magnetic Resonance-Derived Quantification in Asymptomatic Patients With Organic Mitral Regurgitation: Comparison With Doppler Echocardiography-Derived Integrative Approach. Circulation 2018;137:1349-60.

7. Guez D, Boroumand G, Ruggiero NJ, et al. Automated and Manual Measurements of the Aortic Annulus with ECG-Gated Cardiac CT Angiography Prior to Transcatheter Aortic Valve Replacement: Comparison with 3D-Transesophageal Echocardiography. Acad Radiol 2017;24:587-93.

8. Utsunomiya H, Itabashi Y, Kobayashi S, et al. Clinical Impact of Size, Shape, and Orientation of the Tricuspid Annulus in Tricuspid Regurgitation as Assessed by ThreeDimensional Echocardiography. J Am Soc Echocardiogr 2020;33:191-200.e1.

9. Delgado V, Tops LF, Schuijf JD, et al. Assessment of mitral valve anatomy and geometry with multislice computed tomography. JACC Cardiovasc Imaging 2009;2:556-65.

10. Casset C, Jankowski A, Bertrand B, et al. Evaluation of Imaging Strategy to Optimize and Improve Outcome of Transcatheter Aortic Valvular Implantation. Am J Cardiol 2017;120:1633-8.

11. Gulsin GS, Singh A, McCann GP. Cardiovascular magnetic resonance in the evaluation of heart valve disease. BMC Med Imaging 2017;17:67.

12. Myerson SG. Heart valve disease: investigation by cardiovascular magnetic resonance. J Cardiovasc Magn Reson 2012;14:7.

13. Mathew RC, Loffler AI, Salerno M. Role of Cardiac Magnetic Resonance Imaging in Valvular Heart Disease: Diagnosis, Assessment, and Management. Curr Cardiol Rep 2018;20:119.

14. Myerson SG, d'Arcy J, Mohiaddin R, et al. Aortic regurgitation quantification using cardiovascular magnetic resonance: association with clinical outcome. Circulation 2012;126:1452-60.

15. Harris AW, Krieger EV, Kim M, et al. Cardiac Magnetic Resonance Imaging Versus Transthoracic Echocardiography for Prediction of Outcomes in Chronic Aortic or Mitral Regurgitation. Am J Cardiol 2017;119:1074-81.

16. Huded CP, Desai MY. Moderate aortic valve stenosis in patients with left ventricular systolic dysfunction-insights 
on prognosis and the potential role of early aortic valve replacement. J Thorac Dis 2017;9:3590-3.

17. van Gils L, Clavel MA, Vollema EM, et al. Prognostic Implications of Moderate Aortic Stenosis in Patients With Left Ventricular Systolic Dysfunction. J Am Coll Cardiol 2017;69:2383-92.

18. Katbeh A, Ondrus T, Barbato E, et al. Imaging of Myocardial Fibrosis and Its Functional Correlates in Aortic Stenosis: A Review and Clinical Potential. Cardiology 2018;141:141-9.

19. Dweck MR, Joshi S, Murigu T, et al. Midwall fibrosis is an independent predictor of mortality in patients with aortic stenosis. J Am Coll Cardiol 2011;58:1271-9.

20. Musa TA, Treibel TA, Vassiliou VS, et al. Myocardial Scar and Mortality in Severe Aortic Stenosis. Circulation 2018;138:1935-47.

21. Everett RJ, Tastet L, Clavel MA, et al. Progression of Hypertrophy and Myocardial Fibrosis in Aortic Stenosis: A Multicenter Cardiac Magnetic Resonance Study. Circ Cardiovasc Imaging 2018;11:e007451.

22. Tastet L, Tribouilloy C, Marechaux S, et al. Staging Cardiac Damage in Patients With Asymptomatic Aortic Valve Stenosis. J Am Coll Cardiol 2019;74:550-63.

23. Kong WKF, Vollema EM, Prevedello F, et al. Prognostic implications of left ventricular global longitudinal strain in patients with bicuspid aortic valve disease and preserved left ventricular ejection fraction. Eur Heart J Cardiovasc Imaging 2020;21:759-67.

24. Marechaux S, Rusinaru D, Altes A, et al. Prognostic Value of Low Flow in Patients With High Transvalvular Gradient Severe Aortic Stenosis and Preserved Left Ventricular Ejection Fraction: A Multicenter Study. Circ Cardiovasc Imaging 2019;12:e009299.

25. Marques-Alves P, Marinho AV, Teixeira R, et al. Going beyond classic echo in aortic stenosis: left atrial mechanics, a new marker of severity. BMC Cardiovasc Disord 2019;19:215.

26. Christensen NL, Dahl JS, Carter-Storch R, et al. Relation of Left Atrial Size, Cardiac Morphology, and Clinical Outcome in Asymptomatic Aortic Stenosis. Am J Cardiol 2017;120:1877-83.

27. Lee JKT, Franzone A, Lanz J, et al. Early Detection of Subclinical Myocardial Damage in Chronic Aortic Regurgitation and Strategies for Timely Treatment of Asymptomatic Patients. Circulation 2018;137:184-96.

28. Olsen NT, Sogaard P, Larsson HB, et al. Speckle-tracking echocardiography for predicting outcome in chronic aortic regurgitation during conservative management and after surgery. JACC Cardiovasc Imaging 2011;4:223-30.

29. Kusunose K, Agarwal S, Marwick TH, et al. Decision making in asymptomatic aortic regurgitation in the era of guidelines: incremental values of resting and exercise cardiac dysfunction. Circ Cardiovasc Imaging 2014;7:352-62.

30. Kočková R, Línková H, Hlubocká Z, et al. New Imaging Markers of Clinical Outcome in Asymptomatic Patients with Severe Aortic Regurgitation. J Clin Med 2019;8:1654.

31. McGee EC, Gillinov AM, Blackstone EH, et al. Recurrent mitral regurgitation after annuloplasty for functional ischemic mitral regurgitation. J Thorac Cardiovasc Surg 2004;128:916-24.

32. Patzelt J, Zhang W, Sauter R, et al. Elevated Mitral Valve Pressure Gradient Is Predictive of Long-Term Outcome After Percutaneous Edge-to-Edge Mitral Valve Repair in Patients With Degenerative Mitral Regurgitation (MR), But Not in Functional MR. J Am Heart Assoc 2019;8:e011366.

33. Kwon DH, Kusunose K, Obuchowski NA, et al. Predictors and Prognostic Impact of Progressive Ischemic Mitral Regurgitation in Patients With Advanced Ischemic Cardiomyopathy: A Multimodality Study. Circ Cardiovasc Imaging 2016;9:e004577.

34. Lancellotti P, Tribouilloy C, Hagendorff A, et al. Recommendations for the echocardiographic assessment of native valvular regurgitation: an executive summary from the European Association of Cardiovascular Imaging. Eur Heart J Cardiovasc Imaging 2013;14:611-44.

35. Myerson SG, d'Arcy J, Christiansen JP, et al. Determination of Clinical Outcome in Mitral Regurgitation With Cardiovascular Magnetic Resonance Quantification. Circulation 2016;133:2287-96.

36. Loghin C, Loghin A. Role of imaging in novel mitral technologies-echocardiography and computed tomography. Ann Cardiothorac Surg 2018;7:799-811.

37. Liu B, Edwards NC, Neal DAH, et al. A prospective study examining the role of myocardial Fibrosis in outcome following mitral valve repair IN DEgenerative mitral Regurgitation: rationale and design of the mitral FINDER study. BMC Cardiovasc Disord 2017;17:282.

38. Kim HM, Cho GY, Hwang IC, et al. Myocardial Strain in Prediction of Outcomes After Surgery for Severe Mitral Regurgitation. JACC Cardiovasc Imaging 2018;11:1235-44.

39. Kusunose K, Popović ZB, Motoki H, et al. Prognostic significance of exercise-induced right ventricular dysfunction in asymptomatic degenerative mitral regurgitation. Circ Cardiovasc Imaging 2013;6:167-76. 
40. Nunes MC, Handschumacher MD, Levine RA, et al. Role of LA shape in predicting embolic cerebrovascular events in mitral stenosis: mechanistic insights from 3D echocardiography. JACC Cardiovasc Imaging 2014;7:453-61.

41. Wunderlich NC, Beigel R, Ho SY, et al. Imaging for Mitral Interventions: Methods and Efficacy. JACC Cardiovasc Imaging 2018;11:872-901.

42. Cho DK, Ha JW, Chang BC, et al. Factors determining early left atrial reverse remodeling after mitral valve surgery. Am J Cardiol 2008;101:374-7.

43. Verdonk C, Cimadevilla C, Lepage L, et al. Systematic transoesophageal echocardiography after mitral valve replacement: Rates and determinants of paravalvular regurgitation. Arch Cardiovasc Dis 2018;111:528-33.

44. Abramowitz Y, Kazuno Y, Chakravarty T, et al. Concomitant mitral annular calcification and severe aortic stenosis: prevalence, characteristics and outcome following transcatheter aortic valve replacement. Eur Heart J 2017;38:1194-203.

45. Uretsky S, Gillam L, Lang R, et al. Discordance between echocardiography and MRI in the assessment of mitral regurgitation severity: a prospective multicenter trial. J Am Coll Cardiol 2015;65:1078-88.

46. Suh YJ, Hong GR, Han K, et al. Assessment of mitral paravalvular leakage after mitral valve replacement using cardiac computed tomography: comparison with surgical findings. Circ Cardiovasc Imaging 2016;9:e004153.

Cite this article as: Zheng R, Kusunose K. Review: application of current imaging modalities in the management of left-sided valvular heart disease. Cardiovasc Diagn Ther 2021;11(3):793803. doi: 10.21037/cdt.2020.02.04
47. Nucifora G, Tantiongco JP, Crouch G, et al. Changes of left ventricular mechanics after trans-catheter aortic valve implantation and surgical aortic valve replacement for severe aortic stenosis: A tissue-tracking cardiac magnetic resonance study. Int J Cardiol 2017;228:184-90.

48. Takagi H, Umemoto T. Impact of paravalvular aortic regurgitation after transcatheter aortic valve implantation on survival. Int J Cardiol 2016;221:46-51.

49. Athappan G, Patvardhan E, Tuzcu EM, et al. Incidence, predictors, and outcomes of aortic regurgitation after transcatheter aortic valve replacement: meta-analysis and systematic review of literature. J Am Coll Cardiol 2013;61:1585-95.

50. Ribeiro HB, Orwat S, Hayek SS, et al. Cardiovascular Magnetic Resonance to Evaluate Aortic Regurgitation After Transcatheter Aortic Valve Replacement. J Am Coll Cardiol 2016;68:577-85.

51. Frick M, Meyer CG, Kirschfink A, et al. Evaluation of aortic regurgitation after transcatheter aortic valve implantation: aortic root angiography in comparison to cardiac magnetic resonance. EuroIntervention 2016;11:1419-27.

52. Chew PG, Dobson LE, Garg P, et al. CMR quantitation of change in mitral regurgitation following transcatheter aortic valve replacement (TAVR): impact on left ventricular reverse remodeling and outcome. Int J Cardiovasc Imaging 2019;35:161-70. 